\title{
Catalytic Deracemization of Allenes
}<smiles>CCCCC/C=C\C=C\C=C1\CCCNC1=O</smiles>

Selected examples:

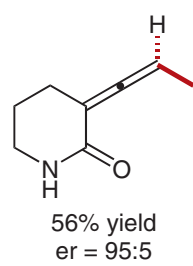

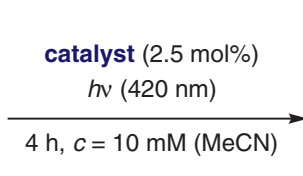<smiles>C=CC1CCCNC1=O</smiles>

17 examples $52-100 \%$ yield er from $94.5: 5.5$ to $98.5: 1.5$

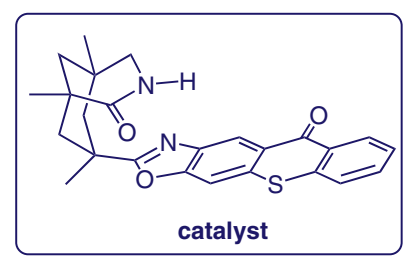

catalyst

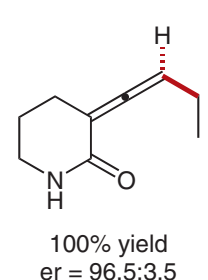

Mechanistic description on the basis of DFT calculations:

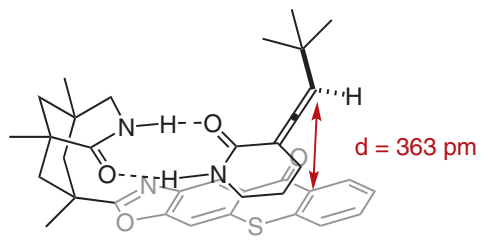

Key words

photocatalysis

deracemization

allenes

sensitized excitation

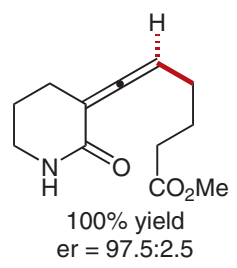

er $=96.5: 3.5$
Significance: Bach and co-workers report an allene deracemization reaction catalyzed by an organic chiral sensitizer under visible light. By using this method, several racemic allenes were converted into enantiomers with yields of $\leq 100 \%$ and er values of $\leq 98.5: 1.5$. DFT calculations are also provided to support the proposed mechanistic description.

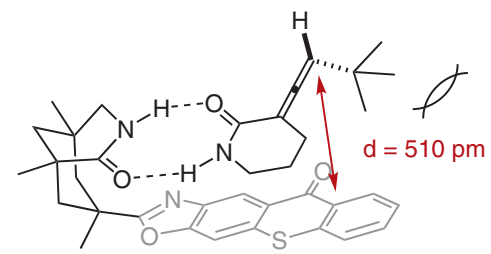

Comment: Light-driven deracemization of chiral compounds might be implicated in the origin of early-stage chirality. The present unprecedented discovery presents an example to support this hypothesis. With different substrate classes, solutions to generate chiral centers might be possible in cases where thermally controlled catalytic deracemizations are entropically disfavored. 